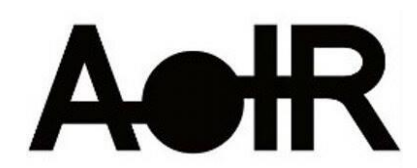

Selected Papers of \#AoIR2021:

The 22nd Annual Conference of the

Association of Internet Researchers

Virtual Event / 13-16 Oct 2021

\title{
Exploring Video-Game Production's Contingency on Live-Streaming Platforms: The Case of Twitch
}

\author{
Papaevangelou Charis \\ Université Toulouse III - Paul Sabatier (LERASS/JOLT-ETN) \\ Elina Roinioti \\ Panteion University of Political and Social Sciences
}

\section{Introduction}

This article studies the cultural contingency (Nieborg \& Poell, 2018) of videogame production on Amazon's live-streaming platform, Twitch. It looks at this phenomenon from a political-economic perspective to unearth Twitch's platformisation strategy to better understand what it means for the video-game industry. Subsequently, we wish to grasp what dependencies are created and how it is made possible. We argue that Twitch is transforming into an integral part of the video-game production cycle by expanding its services to every stage of a game's life cycle.

\section{Literature Review}

Scholars have rigorously engaged with platforms or the so-called "platform society" (van Dijck et al., 2018), in which socio-technical infomediaries have created "complex multisided market configurations" (Nieborg \& Poell, 2018, p. 1) in an organised, curated and non-neutral way (Gillespie, 2010). Subsequently, platformisation signifies the infrastructural embeddedness of platforms (Zhang, 2020; Plantin et al., 2018), supported by a business strategy of expanding beyond their services' boundaries to standardise appropriation, processing and exploitation of data (Helmond, 2015), resulting in a dependency of content creators on digital platforms (Papaevangelou, 2018).

One of the most popular and thus thoroughly examined case study, is Twitch.Tv. People's motives for watching streamers (Taylor, 2018), Twitch community of practice (Consalvo \& Phelps, 2021) or Twitch as a virtual third space (Hamilton et al, 2014), are some of the most prominent approaches on the subject. Live-streaming and eSports (Hamari \& Sjöblom, 2017) and "playbour" (Postigo, 2016; Woodcock \& 
Johnson, 2019) have also been well examined. Although some have argued that Twitch has democratised access to the game industry (Johnson \& Woodcock, 2018), the affordances and the economic implications of the platform (Partin 2020; Roinioti \& Papaevangelou, 2019; Kaytoue et al., 2012), the gamification (Siutila, 2018) or, even, gamblification (Abarbanel \& Johnson, 2020) mechanics constitute aspects of a phenomenon that is still evolving and changing.

\section{Methodology}

This paper examined Twitch's "Game Developer Playbook" on two levels: its content and its discourse. First, we coded the Playbook to identify features that Twitch proposed as solutions for game developers and then, labelled them according to which stage of a video-game's production cycle they arguably affect. We must emphasise that we based our categorisation on Twitch's broad "three phases," which is an indicative distilment of a typical game development cycle.

Second, we attempted to critically analyse the discourse dictated by Twitch: following the tradition of semiotically analysing software affordances (Curinga, 2014) or scripts (Ask et al., 2019), we analysed Twitch's document in order to infer how the platform is shaping up to accommodate game developers not only as streamers but also as customers.

\section{Findings \& Discussion}

\begin{tabular}{|c|c|c|}
\hline Feature & Brief Description & $\begin{array}{c}\text { Production } \\
\text { Phases }\end{array}$ \\
\hline Identity & $\begin{array}{c}\text { Serves as a remote access point for } \\
\text { Twitch (e.g., as Facebook Login) }\end{array}$ & Development \\
\hline $\begin{array}{c}\text { Bounty } \\
\text { Board }\end{array}$ & $\begin{array}{c}\text { Sponsored rewardable tasks for } \\
\text { streamers to complete }\end{array}$ & $\begin{array}{c}\text { Road to launch \& } \\
\text { Live Games }\end{array}$ \\
\hline $\begin{array}{c}\text { Interactive } \\
\text { Extensions }\end{array}$ & $\begin{array}{c}\text { Interactive Extensions (e.g., overlays) } \\
\text { for streams }\end{array}$ & $\begin{array}{c}\text { Road to launch \& } \\
\text { Live Games }\end{array}$ \\
\hline Drops & $\begin{array}{c}\text { Time or event-based rewards (e.g., in- } \\
\text { game items) for viewers or streamers }\end{array}$ & $\begin{array}{c}\text { Road to launch \& } \\
\text { Live Games }\end{array}$ \\
\hline \multicolumn{2}{|c|}{ Table 1- Twitch's Core Game Production Features } \\
\hline
\end{tabular}

The features in Table 1, demonstrate how Twitch has infiltrated the game production cycle with infrastructural but also metagaming elements. Specifically: Identity essentially enables the communication between Twitch and video games under development; the Bounty Board incentivises streamers to promote partnered video games; Drops and Interactive Extensions seek to acquire more viewers, as well as make streamers stream certain video games and, thus, convert some viewers into players or as Twitch mentions, into payers; Drops, particularly, also drive more Amazon Prime subscriptions. Game developers can then have access to game data, like viewership 
metrics, to gauge how streamer-friendly their game is and optimise it, as well as utilise said metrics to target specific streamers to advertise their game.

Similar to Free-to-Play games, in which data and users' behavioural preferences are used to fuel game design and create the so-called "game as service experience" (Ball \& Fordham, 2018). Game developers are incentivised to apply these features in their game design, thus creating an economic feedback loop that a) aspires to increase user acquisition, retention and revenue, b) locks-in game developers and viewers alike, and c) "platformises" the gaming experience.

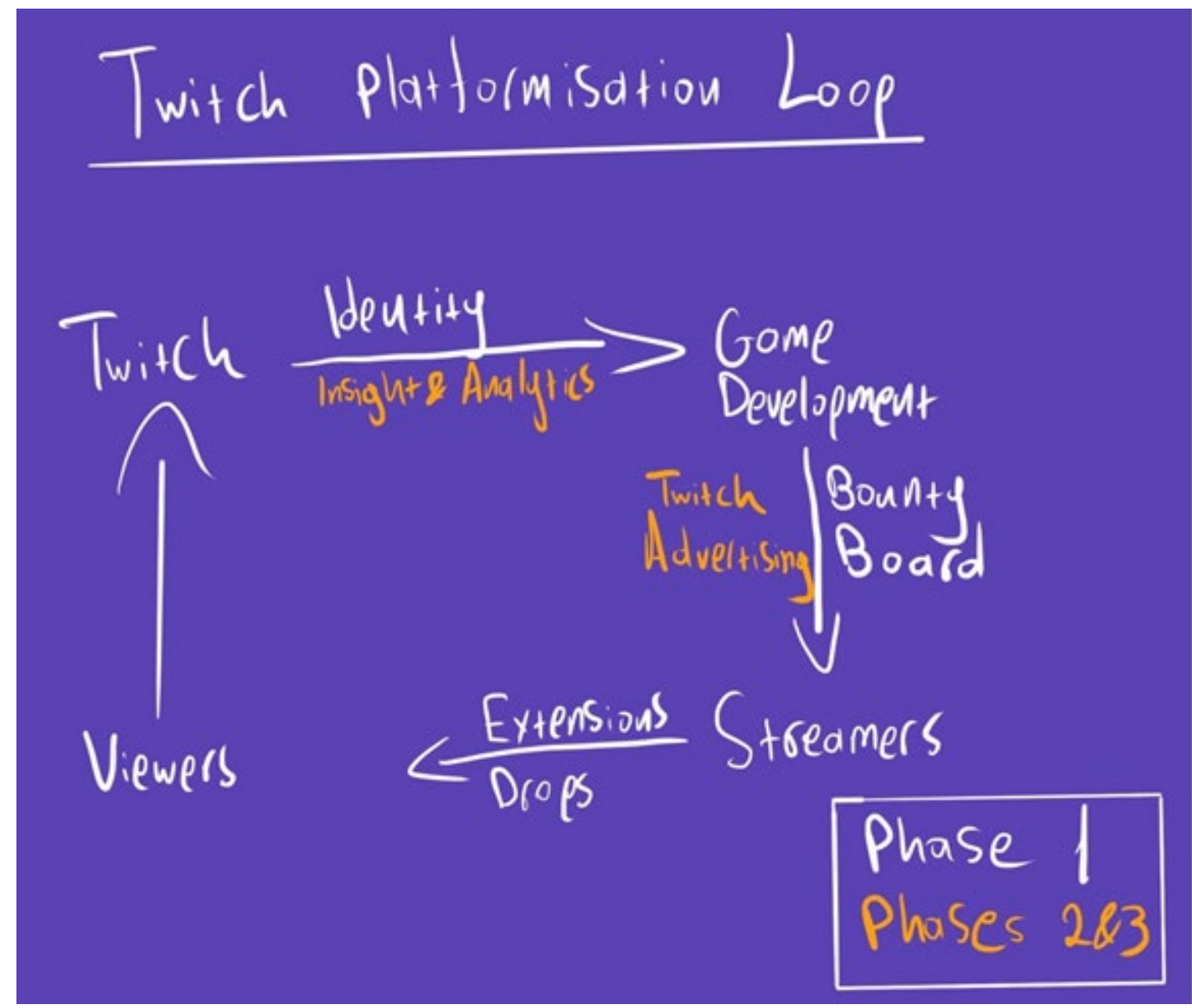

Figure 1 - Twitch's Platformisation Loop (Authors' formulation)

Furthermore, from a streamer's perspective, choosing a game to stream is not related to the content per se, but rather to the popularity of the game. Online tools like TwitchTracker or TwitchStrike provide information about viewership and popularity of a game. In Game Developers Conference (GDC) 2014, the streamer Sean Plott or "Day[9]TV" talked about how skill-based or non-linear narrative games (Zukowski, 2013) are more pleasurable to watch. Likewise, Sjöblom et al. 
(2017) have talked about the "spectator experience" and how the RTS genre lacks this element, initiating thus a discussion about mechanics, game genres and live-streaming.

This kind of platform embeddedness in content creation is not new: Netflix, streaming technologies, the algorithmic-driven model of viewership and subscription membership, have had a profound impact on the contemporary TV industry, exploiting what Burroughs (2018) has mentioned as the "industry lore" (Havens, 2013). Now Netflix has become a content creator carrying the "badge" of quality TV (ibid), while disrupting traditional means of distribution and production.

Accordingly, one cannot help but wonder if Twitch is claiming the same spot for videogame content creation; and, if this is indeed part of Twitch's strategy, what kind of content creation should we anticipate? Are game development studios ready to be "Twitched?" One thing is certain: we have yet to fully grasp the consequences of livestreaming and Twitch on the video-game industry and beyond.

\section{References}

Ask, K., Spilker, H. S., \& Hansen, M. (2019). The politics of user-platform relationships: Co-scripting live-streaming on Twitch.tv. First Monday. https://doi.org/10.5210/fm.v24i7.9648

Burroughs, B. (2018). House of Netflix: Streaming media and digital lore. Popular Communication, 17(1), 1-17. https://doi.org/10.1080/15405702.2017.1343948

Consalvo, M. \& Phelps, A. (2021). 6. Game Development Live on Twitch : Observations of Practice and Educational Synergies. In O. Sotamaa \& J. Svelch (Ed.), Game Production Studies (pp. 123-140). Amsterdam: Amsterdam University Press. https://doi.org/10.1515/9789048551736-008

Curinga, M. X. (2014). Critical analysis of interactive media with software affordances. First Monday. https://doi.org/10.5210/fm.v19i9.4757

Gillespie, T. (2010). The politics of 'platforms'. New Media \& Society, 12(3), 347-364. https://doi.org/10.1177/1461444809342738

Hamari, J., \& Sjöblom, M. (2017). What is eSports and why do people watch it? Internet Research, 27(2), 211-232. https://doi.org/10.1108/IntR-04-2016-0085

Hamilton, W.A., Garretson, O. and Kerne, A. (2014). Streaming on Twitch: Fostering participatory communities of play within live mixed media. Proceedings of the 32nd Annual ACM conference on human factors in computing systems

Havens, T. (2013). Black Television Travels: African American Media Around the Globe. New York University Press.

Helmond, A. (2015). The Platformization of the Web: Making Web Data Platform Ready. Social Media + Society, 1(2), 205630511560308. https://doi.org/10.1177/2056305115603080

Nieborg, D. B., \& Helmond, A. (2019). The political economy of Facebook's platformization in the mobile ecosystem: Facebook Messenger as a platform instance. Media, Culture \& Society, 41(2), 196-218. https://doi.org/10.1177/0163443718818384 
Nieborg, D. B., \& Poell, T. (2018). The platformization of cultural production: Theorizing the contingent cultural commodity. New Media \& Society, 20(11), 4275-4292. https://doi.org/10.1177/1461444818769694

Papaevangelou, C. (2018). "Play, Connect, Create": Delineating Valve's Steam Platformisation Strategy Through its Affordances Faculty of Humanities Theses. https://dspace.library.uu.nl/handle/1874/368625

Partin, W. C. (2020). Bit by (Twitch) Bit: "Platform Capture" and the Evolution of Digital Platforms. Social Media + Society, 6(3), 205630512093398. https://doi.org/10.1177/2056305120933981

Plantin, J.-C., Lagoze, C., Edwards, P. N., \& Sandvig, C. (2018). Infrastructure studies meet platform studies in the age of Google and Facebook. New Media \& Society, 20(1), 293-310. https://doi.org/10.1177/1461444816661553

Postigo, H. (2016). The socio-technical architecture of digital labor: Converting play into YouTube money. New Media \& Society, 18(2), 332-349. https://doi.org/10.1177/1461444814541527

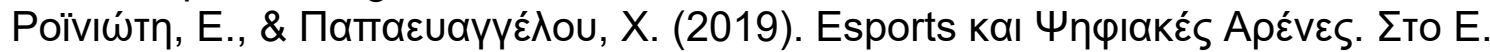

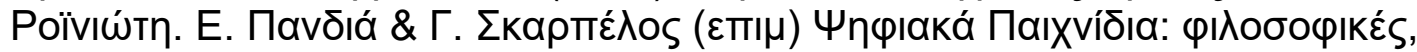

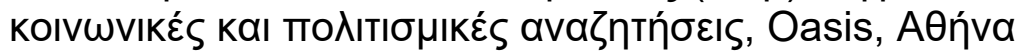

Sjöblom, M., Törhönen, M., Hamari, J., \& Macey, J. (2017). Content structure is king: An empirical study on gratifications, game genres and content type on Twitch. Computers in Human Behavior, 73, 161-171. https://doi.org/10.1016/j.chb.2017.03.036

Suitila, M. (2018). The gamification of gaming streams, GamiFIN Conference 2018, Pori, Finland

Taylor, T. L. (2018). Watch Me Play. Princeton University Press; JSTOR. https://doi.org/10.2307/j.ctvc77jqw

van Dijck, J., Poell, T., \& de Waal, M. (2018). The Platform Society: Public Values in a Connective World. Oxford University Press.

Woodcock, J., \& Johnson, M. R. (2019). The Affective Labor and Performance of Live Streaming on Twitch.tv. Television \& New Media, 20(8), 813-823. https://doi.org/10.1177/1527476419851077

Zhang, Z. (2020). Infrastructuralization of Tik Tok: Transformation, power relationships, and platformization of video entertainment in China. Media, Culture \& Society. https://doi.org/10.1177/0163443720939452

Zukowski, C. (2013). How to make your games better to stream, according to Day[9], Gamasutra, November 5 2013, Accessed 15th July 2021. https://www.gamasutra.com/view/news/204099/How_to_make_your_games_bett er_to_stream_according_to_Day9.php 